\title{
KOMPETENSI GURU PENDIDIKAN AGAMA ISLAM SD NEGERI DI KECAMATAN BATANG ANGKOLA
}

\author{
Nur'Ainun Gulo \\ Sekolah Tinggi Ilmu Ekonomi Labuhanbatu
}

\begin{abstract}
This research was carried out with the aim to find out the competence of Islamic elementary education teachers in the District of Batang Angkola. Based on Minister of Religion Regulation No. 16 of 2010, wherein it is explained that there are five teacher competencies, namely pedagogical competence, personal competence, social competence, and professional competence and leadership competency because this research is specifically for PAI teachers, so it is added with religious competence. The purpose of this study provides an overview of the competence of PAI teachers.

The research method used in this research is descriptive qualitative method, the research used to find out or describe the reality of the events under study or research conducted on independent variables without making comparisons with other variables. Data collection techniques carried out in the form of observation, interviews with all informants who have been determined purposively and document study. Data analysis technique is done by data reduction, presentation and conclusion drawing.

Based on the results of the study, it can be concluded that the Competency Profile of PAI Teachers in Public Elementary Schools in Batang Angkola Subdistrict are as follows: (1) Pedagogical competencies are categorized as good, except for indicators of understanding towards learners and the implementation of educative and dialogical learning; (2) Personality competencies are categorized as good, except for the indicators of presenting themselves as individuals who are steady, stable, mature, and become role models; (3) Social competence is categorized as good, with the exception of indicators of ability to communicate, especially with cues and adaptation in places throughout the territory of the Republic of Indonesia which have social and cultural diversity; (4) Professional competence is categorized quite well, where PAI teachers can master the subject matter and have the ability to deliver material widely; (5) Leadership competencies are categorized as good; (6) Religious competence can be categorized as good.

Because there are still a number of indicators that are still low or not good in each competency, the recommendations of this study are (1) For the Department of
\end{abstract}


Education in the South Tapanuli Regency to make policies that are in line with the ability of special teachers in the Batang Angkola District area; (2) School principals are expected to improve the quality of PAI teachers; (3) For PAI teachers further enhance their teaching.

Keywords: Pedagogic Competence, Personality competence, Social Competence, Professional competence, Leadership competence and Religious competence.

\section{A. PENDAHULUAN}

Dalam dunia pendidikan, sedikitnya terdapat tiga unsur atau syarat utama yang harus diperhatikan dalam pembangunan pendidikan agar dapat berkontribusi terhadap peningkatan kualitas Sumber Daya Manusia (SDM), yaitu sarana, buku yang berkualitas serta guru dan tenaga kependidikan yang professional. Keberhasilan guru dalam melaksanakan pembelajaran dapat dilihat dari pencapaian yang ada telah mencapai secara keseluruhan.jika kriteria telah tercapai, berarti pekerjaan seorang guru dianggap memiliki kualitas kerja yang baik. Oleh karena itu, sebagai guru bukan hanya dituntut memiliki ijazah saja akan tetapi guru juga dituntut agar memiliki kompetensi. Kompetensi merupakan hal yang penting dimiliki guru agar dapat melaksanakan tugasnya sebagai pendidik dan pengajar secara efektif dan efisien. Kompetensi merupakan kemampuan atau kecakapan melakukan sesuatu.

Terkait dengan Standar Kualifikasi Akademik dan Kompetensi Guru, dalam Permenang Nomor 16 Tahun 2010 yang menyatakan bahwa: "kompetensi guru 
terdapat lima yaitu: kompetensi pedagogik, kepribadian, sosial,dan professional serta kompetensi kepemimpinan.

Guru PAI harus memiliki kompetensi yang sama dengan guru pada umumnya, tetapi juga harus memiliki ciri khas tersendiri. Kompetensi umum yang dimaksud, yaitu guru PAI harus memiliki kompetensi pedagogik, kompetensi kepribadian, kompetensi sosial, dan kompetensi professional serta kompetensi kepemimpinan. Namun sebagai guru PAI harus memiliki kompetensi khusus, yaitu kompetensi keagamaan.

Pada kenyataannya dilapangan, guru PAI masih jauh dari kompetensi yang diharapkan. Dimana masih terdapat beberapa masalah yang dihadapi guru PAI. Banyaknya guru PAI yang belum di sertifikasi, keberagaman dan pengetahuan sebagian guru PAI, dan pembinaan yang di lakukan oleh pemerintah tidak sesuai dengan apa yang menjadi kebutuhan guru PAI.

Kecamatan Batang Angkola merupakan salah satu kecamatan yang terdapat di wilayah Kabupaten Tapanuli Selatan yang sedang gencar-gencarnya melakukan mutu peningkatan kualitas pendidikan, khususnya di bidang tenaga pengajar atau guru untuk meningkatkan kompetensi. Hal ini dibuktikan dengan banyaknya guru-guru yang mengikuti sertifikasi. Selain itu, permasalahan guru PAI yang ada di kecamatan Batang Angkola adalah adanya guru-guru PAI yang belum memenuhi standar 
kualifikasi, guru PAI yang melakukan tindakan kekerasan jika murid melakukan kesalahan, dan melalaikan tugas mengajar.

Berdasarkan permasalahan di atas, maka perlu dilakukan penelitian secara mendalam mengenai Profil Kompetensi Guru Pendidikan Agama Islam guna memperoleh deskripsi mengenai hal tersebut. Adapun permasalahan yang dimaksud dijabarkan dalam pertanyaan-pertanyaan penelitian.

(1) Bagaimanakan kompetensi pedagogik guru Pendidikan Agama Islam (PAI) SD Negeri di Kecamatan Batang Angkola?

(2) Bagaimanakan kompetensi kepribadian guru Pendidikan Agama Islam (PAI) SD Negeri di Kecamatan Batang Angkola?

(3) Bagaimanakan kompetensi sosial guru Pendidikan Agama Islam (PAI) SD Negeri di Kecamatan Batang Angkola?

(4) Bagaimanakan kompetensi profesional guru Pendidikan Agama Islam (PAI) SD Negeri di Kecamatan Batang Angkola?

(5) Bagaimana kompetensi kepemimpinan guru Pendidikan Agama Islam SD Negeri di Kecamatan Batang Angkola?

(6) Bagaimana kompetensi keagamaan guru Pendidikan Agama Islam (PAI) SD Negeri di Kecamatan Batang Angkola? 


\section{JURNAL ECOBISMA VOL 2 NO. 1 JAN 2015}

Tujuan penelitian ini adalah untuk (1) Untuk mengetahui kompetensi pedagogik guru Pendidikan Agama Islam (PAI) SD Negeri di Kecamatan batang Angkola, (2) Untuk mengetahui kompetensi kepribadian guru Pendidikan Agama Islam (PAI) SD Negeri di Kecamatan Batang Angkola, (3) Untuk mengetahui kompetensi sosial guru Pendidikan Agama Islam (PAI) SD Negeri di Kecamatan Batang Angkola, (4) Untuk mengetahui kompetensi profesional guru Pendidikan Agama Islam (PAI) SD Negeri di Kecamatan Batang Angkola,(5) Untuk mengetahui kompetensi kepemimpinan guru Pendidikan Agama Islam (PAI) SD Negeri di Kecamatan Batang Angkola,(6) Untuk mengetahui kompetensi keagamaan guru Pendidikan Agama Islam (PAI) SD Negeri di Kecamatan Batang Angkola.

\section{B. KAJIAN PUSTAKA}

\section{Pengertian Kompetensi Guru}

Kata kompetensi dalam bahasa Indonesia merupakan serapan dari bahasa Inggris yaitu competence yang berarti person helping ability, power, authority, skill,knowledge, too do what is need. Pendapat lainnya menyebutkan bahwa kompetensi merupakan peleburan dari pengetahuan (daya piker), sikap (daya kalbu), dan keterampilan (daya pisik) yang diwujudkan dalam bentuk perbuatan. Atau dengan kata lain, kompetensi merupakan perpaduan dari penguasaan pengetahuan, keterampilan, nilai dan sikap yang direfleksikan dalam kebiasaan berpikir dan 


\section{JURNAL ECOBISMA VOL 2 NO. 1 JAN 2015}

bertindak dalam melaksanakan tugas/pekerjaan (Sagala,2013).

Menurut Majid (2007), kompetensi merupakan seperangkat tindakan inteligen penuh tanggung jawab yang harus dimiliki seseorang sebagai syarat untuk dianggap mampu melaksanakan tugas-tugas dalam bidang pekerjaan tertentu. Usman (2006) memaknai kompetensi sebagai suatu hal yang mengambarkan kualifikasi atau kemampuan seseorang baik secara kualitatif maupun kuantitatif. Dan menurut Soehertian (1990), kompetensi adalah berupa kemampuan melaksanakan sesuatu yang diperoleh melalui pendidikan atau latihan. Kemudian Soewando(2002), menjelaskan bahwa kompetensi adalah sebagian pengetahuan, keterampilan dan nilai-nilai dasar yang direfleksikan dalam kebiasaan berpikir dan bertindak.

Berdasarkan pengertian kompetensi atau kemampuan tersebut maka dapat dipahami bahwa kompetensi adalah suatu penguasaan terhadap suatu tugas, keterampilan, sikap yang diperlukan unutk menunjang kualitas guru yang sebenarnya yang ditunjukkan dalam bentuk penguasaan pengetahuan dan perbuatan secara professional dalam menjalankan fungsinya sebagai guru.

Guru adalah sebagai orang yang dapat digugu dan ditiru atau semua petugas yang terlibat dalam tugas-tugas kependidikan (Nurdin,2002). Dan menurut UU dan PP tentang pendidikan No.14 Tahun 2005, menjelaskan bahwa guru adalah "pendidik profesional dengan tugas utama mendidik, mengajar, membimbing, mengarahkan, 
melatih, menilai dan mengevaluasi peserta didik pada pendidikan anak usia dini jalur formal, pendidikan dasar dan pendidikan menengah”.

Dari uraian di atas, maka dapat disimpulkan bahwa kompetensi guru adalah seperangkat penguasaan kemampuan yang harus ada dalam diri seorang guru agar dapat mewujudkan kinerja secara cepat dan efektif.

\section{Jenis-jenis Kompetensi Guru}

\section{a. Kompetensi Pedagogik}

Menurut Badan Standar Nasional ( Musfah,2011), kompetensi pedagogik adalah kemampuan mengelola peserta didik yang meliputi; pemahaman wawasan dan landasan pendidikan, pemahaman tentang peserta didik, pengembangan kurikulum/silabus, perancangan pembelajaran, pelaksanaan pembelajaran yang mendidik dan dialogis,evaluasi hasil belajar dan pengembangan peserta didik untuk mengaktualisasikan berbagai potensi yang dimilikinya.

\section{b. Kompetensi Kepribadian}

Dalam Standar Nasional Pendidikan (Musfah,2011) kompetensi kepribadian adalah kemampuan kepribadian yang mantap, stabil, dewasa, arif dan berwibawa, menjadi teladan bagi murid dan berakhlak mulia.

\section{c. Kompetensi Sosial}

Dalam Standar Nasional Pendidikan, penjelasan Pasal 28 ayat (3) butir d 
(Rusman,2011) kompetensi sosial adalah kemampuan guru sebagai bagian dari masyarakat untuk berkomunikasi dan bergaul secara efektif dengan murid, sesama pendidik, tenaga pendidikan, orang tua/ wali murid dan masyarakat sekitar.

\section{d. Kompetensi Profesional}

Kompetensi professional adalah kemampuan penguasaan materi pembelajaran secara meluas dan mengkaji yang memungkinkannya membimbing peserta didik mengetahui standar yang diterapkan dalam standar nasional pendidikan (Aqib,2006).

\section{e. Kompetensi Kepemimpinan}

Kompetensi kepemimpinan adalah kemampuan seorang guru dalam melaksanakan amanah dan tanggung jawab. Guru agama berbeda dengan guru bidang studi lainnya, disamping melaksanakan tugas pengajaran juga melaksanakan tugas pembinaan bagi peserta didik, membantu pembentukan kepribadian, pembinaan akhlak serta menumbuh kembangkan keimanan dan ketaqwaan pada peserta didik.

\section{f. Kompetensi Keagamaan}

Kompetensi keagamaan guru dimaksudkan untuk menyebutkan komitmen beragama guru, bisa berupa nilai-nilai, sikap-sikap dan perilaku beragama. Menurut Glock \& Stark, komitmen beragama muncul dalam lima dimensi, yaitu ideologis, intelektual, eksperiensial, ritualistik dan konsekuensial. Komitmen beragama pun 
sering diukur dari : ketaatan melaksanakan perintah dan menjauhi larangan Allah, keakraban dengan Al-Qur'an dan Hadist dan ulama, kegairahan dalam mempelajari ilmu agama dan aktivitas dalam kegiatan keagamaan

\section{METODOLOGI PENELITIAN}

\section{Metode dan Pendekatan Penelitian}

Penelitian ini adalah penelitian lapangan (fiel research) yaitu melakukan penelitian langsung ke lokasi untuk mendapatkan dan menyimpulkan data. Penelitian yang dilaksanakan di lapangan adalah meneliti masalah yang sifatnya kualitatif, yakni prosedur data penelitian yang menghasilkan data deskriptif berupa kata-kata yang tertulis atau lisan dari orang-orang dan perilaku yang diamati.

Penelitian kualitatif adalah suatu penelitian yang ditujukan untuk mendeskripsikan dan menganalisis penomena, peristiwa, aktifitas sosial, sikap, kepercayaan, persepsi, pemikiran orang secara individual mau maupun kelompok.

\section{Prosedur Penelitian}

Penelitian yang menggunakan pendekatan kualitatif terdapat tiga tahap yang akan dilakukan: (a) Tahap orientasi, merupakan penelitian awal untuk memperoleh gambaran permasalahan yang lebih lengkap dan fokus, (b) Tahap Eksplorasi, yaitu mengumpulkan data yang berkenaan dengan fokus dan pernyataan penelitian selaras 
dengan tujuan penelitian dilaksanakan secara intensif, (c) Tahap member chek, merupakan verifikasi dengan mengecek keabsahan atau validasi data.

\section{Subjek Penelitian}

Subjek penelitian adalah subjek yang dituju untuk diteliti oleh peneliti (Arikunto,2010). Dalam penelitian ini terdapat dua macam sumber data yaitu data primer (seluruh PAI SD Negeri di Kecamatan Batang Angkola) dan data skunder atau pendukung ( Kepala sekolah, guru kelas dan siswa).

\section{Strategi Pengumpulan Data}

\section{a. Observasi}

Observasi adalah penelitian ilmiah yang tidak hanya sekedar meninjau atau melihat-lihat saja, tetapi mengamati secara cermat dan sistematis sesuai dengan panduan yang telah dibuat (Kholil,2006).

\section{b. Wawancara}

Wawancara merupakan sebuah percakapan antara dua orang atau lebih yang mana pertanyaannya diajukan oleh peneliti kepada subjek penelitian untuk dijawab (Danim,2002).

\section{c. Studi Dokumen}

Menurut Arikunto (2006), dokumen adalah barang-barang tertulis dimana dalam pelaksanaannya peneliti menyelidiki benda-benda tertulis seperti: buku-buku, 
majalah,peraturan-peraturan,notulen rapat, catatan harian dan sebagainya.

\section{Teknik Analisa Data}

Moleong (2010), mengemukakan bahwa analisa data adalah proses mengorganisasikan dan mengurutkan data ke dalam pola, kategori dan satuan dasar sehingga dapat ditemukan tema dan dapat dirumuskan hipotesis kerja seperti yang disarankan oleh data. Dan setelah data-data dikumpulkan tahap selanjutnya adalah analisa data, diamana dalam penelitian ini analisa data dilakukan melalui; mereduksi data,penyajian data dan penarika kesimpulan.

\section{Teknik Penjamin Keabsahan Data}

Untuk menetapkan keabsahan data dalam penelitian ini, peneliti merujuk pada pendapat Moleong (2010), dimana terdapat empat kriteria yang digunakan: derajat kepercayaan (creadibility), keteralihan (transferability), ketergantungan (confimability), dan kepastian (dependability).

\section{HASIL PENELITIAN DAN PEMBAHASAN}

Berdasarkan penelitian yang telah dilakukan, maka diperoleh hasil penelitian berdasarkan jawaban responden dan dari pengamatan peneliti dari setiap komponen yang diajukan dan diamati oleh peneliti . Terkait dengan kompetensi guru Pendidikan Agama Islam SD Negeri di Kecamatan Batang Angkola lebih jelasnya dapat dilihat dibawah ini: 


\section{Matriks Implementasi Guru Pendidikan Agama Islam SD Negeri di Kecamatan Batang Angkola}

\begin{tabular}{|c|c|c|c|c|c|}
\hline \multirow{2}{*}{ No } & \multirow[b]{2}{*}{ Kompetensi } & \multirow[b]{2}{*}{ Indikator } & \multicolumn{3}{|c|}{ Keterangan } \\
\hline & & & $\begin{array}{c}\text { Bai } \\
\mathbf{k}\end{array}$ & $\begin{array}{c}\text { Sedan } \\
\mathrm{g}\end{array}$ & $\begin{array}{l}\text { Kuran } \\
\text { g Baik }\end{array}$ \\
\hline \multirow[t]{7}{*}{1.} & \multirow[t]{7}{*}{ K. Pedagogik } & $\begin{array}{l}\text { a. Pemahaman } \\
\text { wawasan dan } \\
\text { landasan pendidikan }\end{array}$ & $\sqrt{ }$ & & \\
\hline & & $\begin{array}{l}\text { b. Pemahaman } \\
\text { terhadap peserta didik }\end{array}$ & & & $\sqrt{ }$ \\
\hline & & $\begin{array}{l}\text { c. Pengembangan } \\
\text { kurikulum }\end{array}$ & $\sqrt{ }$ & & \\
\hline & & $\begin{array}{l}\text { d. Perancangan } \\
\text { pembelajaran }\end{array}$ & $\sqrt{ }$ & & \\
\hline & & $\begin{array}{l}\text { e. Pelaksanaan } \\
\text { pembelajaran yang } \\
\text { mendidik dan dialogis }\end{array}$ & & & $\sqrt{ }$ \\
\hline & & $\begin{array}{l}\text { f. Evaluasi hasil } \\
\text { belajar }\end{array}$ & $\sqrt{ }$ & & \\
\hline & & $\begin{array}{l}\text { g. Pengembangan } \\
\text { peserta didik untuk } \\
\text { mengaktualisasikan } \\
\text { berbagi potensi yang } \\
\text { dimilikinya }\end{array}$ & $\sqrt{ }$ & & \\
\hline \multirow[t]{4}{*}{2.} & \multirow[t]{4}{*}{$\begin{array}{l}\text { K. } \\
\text { Kepribadian }\end{array}$} & $\begin{array}{l}\text { a. Berakhlak } \\
\text { mulia }\end{array}$ & $\sqrt{ }$ & & \\
\hline & & $\begin{array}{l}\text { b. Mantap, } \\
\text { stabil, dan dewasa }\end{array}$ & & $\sqrt{ }$ & \\
\hline & & $\begin{array}{l}\text { c. Arif dan } \\
\text { bijaksana }\end{array}$ & $\sqrt{ }$ & & \\
\hline & & $\begin{array}{ll}\text { d. } & \text { Menjadi }\end{array}$ & & $\sqrt{ }$ & \\
\hline
\end{tabular}


JURNAL ECOBISMA VOL 2 NO. 1 JAN 2015

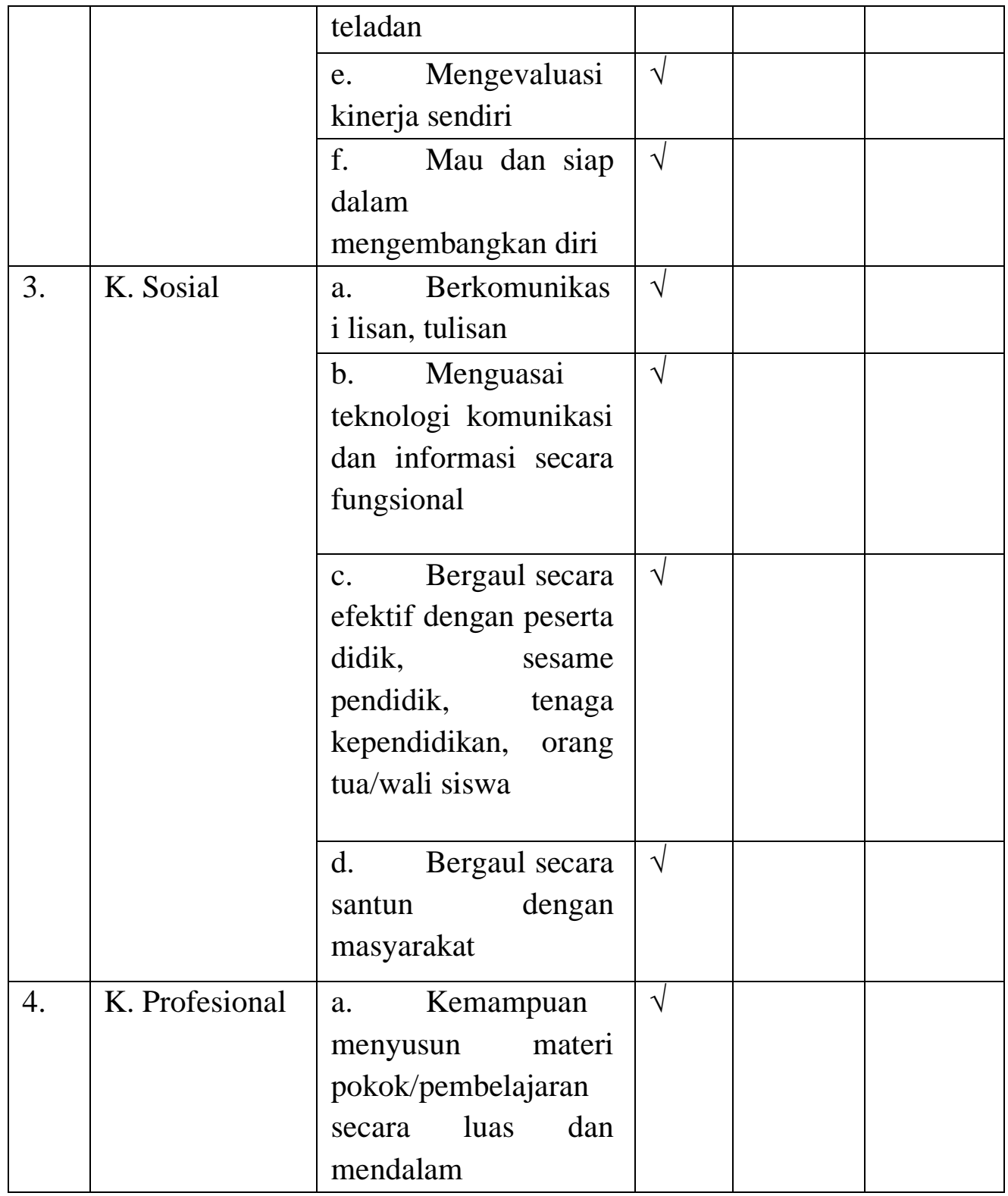


JURNAL ECOBISMA VOL 2 NO. 1 JAN 2015

\begin{tabular}{|c|c|c|c|c|}
\hline & & $\begin{array}{l}\text { b. Kemampuan } \\
\text { penguasaan materi } \\
\text { pokok/ mendalami } \\
\text { pembelajaran secara } \\
\text { luas dan mendalam }\end{array}$ & $\sqrt{ }$ & \\
\hline \multirow[t]{2}{*}{5.} & \multirow[t]{2}{*}{$\begin{array}{l}\text { K. } \\
\text { Kepemimpina } \\
\mathrm{n}\end{array}$} & $\begin{array}{l}\text { a. Kemampuan } \\
\text { membuat perencanaa, } \\
\text { pembudayaan, } \\
\text { pengalaman, ajaran } \\
\text { agama, dan perilaku } \\
\text { akhlak mulia pada } \\
\text { komunitas sekolah } \\
\text { sebagai bagian dari } \\
\text { proses pembelajaran } \\
\text { agama }\end{array}$ & $\sqrt{ }$ & \\
\hline & & $\begin{array}{l}\text { b. Kemampuan } \\
\text { mengorganisir potensi } \\
\text { unsure sekolah secara } \\
\text { sistematis untuk } \\
\text { mendukung } \\
\text { pembudayaan } \\
\text { pengamalan agama } \\
\text { pada komunitas } \\
\text { sekolah }\end{array}$ & & $\sqrt{ }$ \\
\hline
\end{tabular}


JURNAL ECOBISMA VOL 2 NO. 1 JAN 2015

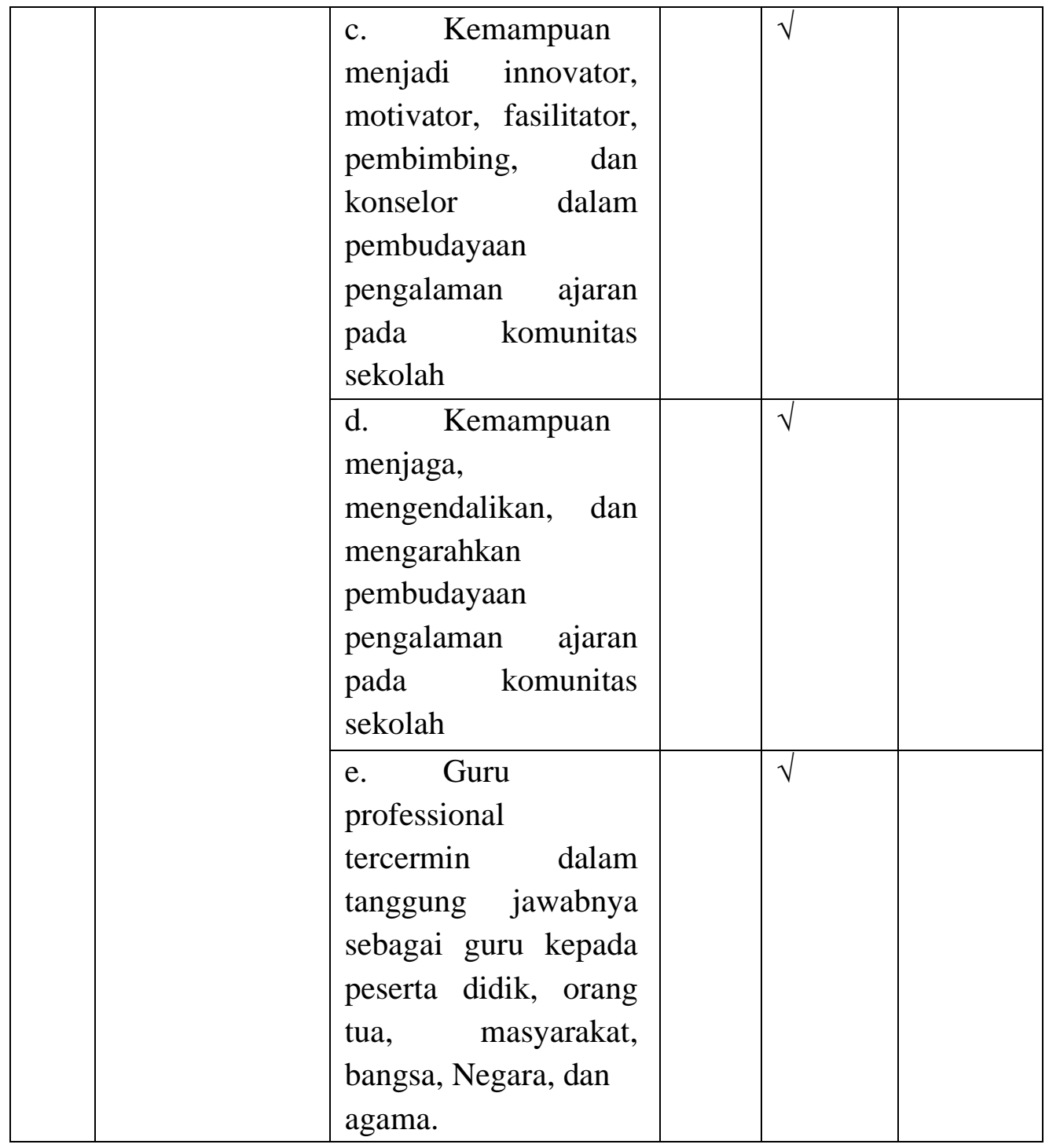


JURNAL ECOBISMA VOL 2 NO. 1 JAN 2015

\begin{tabular}{|l|l|l|l|l|}
\hline 6 & $\begin{array}{l}\text { Kompetensi } \\
\text { keagamaan }\end{array}$ & $\begin{array}{l}\text { a. Memiliki } \\
\text { sifat-sifat } \\
\text { keagamaan/diniyyah } \\
\text { yang baik } \\
\text { b. Memiliki } \\
\text { akhlak yang } \\
\text { mulia/akhlakdiyyah }\end{array}$ & $\sqrt{ }$ & \\
\end{tabular}

\section{E. PENUTUP}

\section{Kesimpulan}

Berdasarkan hasil penelitian yang telah dilakukan oleh peneliti di SD Negeri Negeri di Kecamatan Batang Angkola yang mengkaji tentang Kompetensi Guru Pendidikan Agama Islam SD Negeri di Kecamatan Batang Angkola maka dapat disimpulkan sebagai berikut :

1. Berdasarkan hasil penelitian terkait dengan Kompetensi Pedagogik Guru Pendidikan Agama Islam SD Negeri di Kecamatan Batang Angkola dalam kategori baik, akan tetapi pada indikator pemahaman terhadap peserta didik dan pelaksanaan pembelajaran yang mendidik dan dialogis kurang baik, hal ini dibuktikan dari ketidaksiapan sebagian siswa dalam menerima pelajaran kendaan kelas yang tidak kondusif serta pembelaran yang menimbulkan rasa takut pada siswa oleh sebagian guru.

2. Berdasarkan hasil penelitian Profil Kompetensi Kepribadian Guru Pendidikan Agama Islam SD Negeri di Kecamatan Batang Angkola dalam kategori baik, sedangkan pada indikator menampilkan diri sebagai pribadi yang mantap, stabil, dewasa, dan menjadi teladan kurang baik, karena sebagian guru masih sering terlambat datang ke sekolah, dimana seharusnya seorang guru 
khususnya guru agama harus bisa memberikan contoh yang baik terhadap siswanya baik itu dari segi perkataan maupun perbuatan.

3. Berdasarkan hasil penelitian Kompetensi Sosial Guru Pendidikan Agama Islam SD Negeri di Kecamatan Batang Angkola dalam kategori baik, akan tetapi pada indikator terkait dengan berkomunikasi menggunakan isyarat hanya sebagian guru yang dapat melakukannya.

4. Berdasarkan hasil penelitian Kompetensi Profesional Guru Pendidikan Agama Islam SD Negeri di Kecamatan Batang Angkola dalam kategori baik, dimana guru dapat menguasai bahan pembelajaran serta menyampaikan pembelajaran dengan baik dan menjelasan yang luas.

5. Berdasarkan hasil penelitian Kompetensi Kepemimpinan Guru Pendidikan Agama Islam SD Negeri di Kecamatan Batang Angkola dalam kategori kurang baik, karena banyaknya guru agama yang tidak memiliki kemampuan dalam mengorganisir unsure sekolah secara sistematis serta kurangnya kepedulian sebagian guru terhadap lingkungan sekolahnya, (kemampuan menjadi motivator,innovator, fasilitator dan lain sebagainya)

6. Berdasarkan hasil penelitian Kompetensi Keagamaan Guru Pendidikan Agama Islam SMP Negeri di Kota Bekasi dalam kategori sangat baik.

\section{Saran}

Dari hasil penelitian yang telah dilakukan Penulis masih terdapat beberapa indikator yang masih rendah, oleh karena itu Penulis merekomendasikan kepada:

\section{Dinas Pendidikan Kabupaten Tapanuli Selatan}

Peneliti merekomendasikan kepada Dinas Pendidikan Kabupaten Tapanuli Selatan dapat membuat kebijakan-kebijakan yang lebih sesuai dengan kemampuan guru PAI dan dapat lebih mengawasi dalam setiap kebijakan-kebijakan tersebut, agar 
terjadi hubungan yang baik antara pemerintah dengan guru PAI khususnya guru PAI di wilayah Kecamatan Batang Angkola.

\section{Kepala Sekolah}

Peneliti merekomendasikan kepada Kepala Sekolah agar lebih meningkatkan mutu guru PAI, misalnya dengan mengirim guru untuk mengikuti kegiatan pelatihan, penataran, seminar dan workshop; mengadakan kegiatan pelatihan dan sosialisasi bagi seluruh guru dengan mendatangkan narasumber; mendorong guru untuk melanjutkan studinya ke jenjang pendidikan sebagaimana ditentukan pemerintah; melengkapi berbagai sarana dan media yang dapat menunjang kegiatan pembelajaran; melaksanakan pembelajaran dengan menggunakan berbagai strategi dan metode, meskipun tidak semua sekolah mampu melaksanakan secara efektif; dan lain sebagainya.

\section{Guru Pendidikan Agama Islam (PAI)}

Peneliti merekomendasikan kepada guru Pendidikan Agama Islam untuk lebih meningkatkan kegiatan pengajarannya dengan semaksimal mungkin, melanjutkan tingkat pendidikan, mengikuti berbagai kegiatan MGMP/KKG, pelatihan, penataran, workshop, seminar, dan meningkatkan kinerja, berprilaku yang baik karena guru PAI merupakan panutan dan akan menjadi suri tauladan bagi murid, berhubungan dengan sesama guru dan masyarakat dengan baik.

\section{Prodi PAI dan peneliti berikutnya}

Bagi peneliti yang ingin melakukan penelitian terkait dengan kompetensi guru, baik itu guru agama maupun guru bidang studi lainnya, diharapkan agar dapat melakukan penelitian dengan lebih baik, sehingga pembahasan atau permasalahan terkait dengan kompetensi guru khususnya guru Pendidikan Agama Islam dapat lebih sempurna. 


\section{F. DAFTAR PUSTAKA}

Aqib, Zainal, Pendidikan Karakter: Membangun Perilaku Positif Anak Bangsa, Bandung: Yama Widya, 2006.

Arikunto, Suharsimi, Prosedur Penelitian, Cet. 14, Jakarta: Rineka Cipta: 2010.

Kholil, Syukur, Metodologi Penelitian Komunikasi, Bandung: Cita Pustaka Media, 2006.

Majid, Abdul, Perencanaan Pembelajaran Mengembangkan Standart Komptensi Guru, Cet. 3, Bandung: Remaja Rosdakarya, 2007.

Moleong, Lexcy J. Metodologi Penelitian Kualitatif Edisi Revisi, Bandung: Rosdakarya, 2004.

Musfah, Jejen, Peningkatan Kompetensi Guru Melalui Pelatihan Dan Sumber Teori Dan Praktik, Jakarta: Kencana, 2011.

Nurdin, Syafruddin, Dan Basyiruddin Usman, Guru Professional Dan Implementasi Kurikulum, Jakarta: Ciputat Press, 2002.

Rusman, Model-Model Pembelajaran: Pengembangan Profesionalisme Guru, Jakarta: Raja Grafindo, 2011.

Saefullah, Manajemen Pendidikan Islam, Bandung: Pustaka Cipta, 2012.

Sagala, Syaiful, Kemampuan Professional Guru Dan Tenaga Kependidikan, Bandung: Al-Fabeta, 2013.

Sahertian. Piet A. Dan Ida A. Sahertian, Supervisi Pendidikan Dalam Rangka Program Intensive Education, Jakarta: Bineka Cipta, 1990.

Soewando, Sistem Pengajaran Kurikulum Berbasis Kompetensi, Jakarta: Pusat Kurikulum Balitbong, Depdiknas, 2002.

Suharsimi Arikunto, Prosedur Penelitian Edisi Revisi, Jakarta: Bumi Aksara, 1993. 
Undang-Undang Dan Peraturan Pemerintah Tentang Pendidikan, No. 14 Tahun 2005.

Usman, Moh. Uzer Menjadi Guru Professional, Bandung: Remaja Rosdakarya, 2006) H. 4. 